\title{
ARTIGO
}

\section{A LITERATURA NO PROGRAMA ENSINO MÉDIO INOVADOR: PERSPECTIVAS SOBRE OS SABERES E A PRÁTICA PEDAGÓGICA}

Literature in the Ensino Médio Inovador Program: perspectives on knowledge and educational practice

La Literatura en el Programa Ensino Médio Inovador: perspectivas sobre los saberes y la práctica pedagógica

Silvia Paulo

Universidade Regional de Blumenau - Brasil

Ricardo Inocênio Pereira

Universidade Regional de Blumenau - Brasil

Rita Buzzi Rausch

Universidade Regional de Blumenau - Brasil

Marcia Regina Selpa Heinzle

Universidade Regional de Blumenau - Brasil

\section{Resumo}

Este artigo apresenta resultados de uma pesquisa que tem por objetivo analisar as práticas pedagógicas de professores de literatura no Programa Ensino Médio Inovador (ProEMI). O suporte teórico se baseia em Vygotsky (2002; 2003), Cereja (2005), Cereja e Magalhães (2012), Bakhtin (1988; 1997), bem como a Proposta Curricular de Santa Catarina (2014) e as Diretrizes Curriculares Nacionais para o Ensino Médio (2012). A geração de dados foi por meio de entrevistas semiestruturadas com duas professoras de Língua Portuguesa e Literatura que lecionam no ProEMI numa escola da Rede Estadual de Santa Catarina. As categorias de análise foram: desenvolvimento de saberes pedagógicos; autonomia e protagonismo dos professores e alunos na aprendizagem; e significações da prática pedagógica quanto ao ensino da literatura. Constatou-se, quanto às práticas pedagógicas de professores de literatura promovidas pelo ProEMI, que há uma dificuldade em superar uma postura mais tradicional e de promover um ensino de literatura bem-sucedido. No entanto, algumas pistas presentes nas suas locuções permitem concluir que o ProEMI possibilita algumas inovações, mas estas 
dependem muito dos saberes pedagógicos dos docentes e de sua postura enquanto sujeitos e promotores de autonomia.

Palavras-chave: Ensino de literatura. Práticas pedagógicas. Programa ensino médio inovador.

\begin{abstract}
This article presents results of a research that aims to analyse the educational practices of literature teachers in the Ensino Médio Inovador Program (ProEMI). The theoretical support is based on Vygotsky (2002; 2003), Cereja (2005), Cereja and Magalhães (2012), Bakhtin (1988; 1997), as well as Atualização da Proposta Curricular de Santa Catarina (2014) and Diretrizes Curriculares Nacionais para o Ensino Médio (2012). Data generation was through semi-structured interviews with two Portuguese Language and Literature teachers who teach in the ProEMI, in a school of Santa Catarina State network. The analysis categories were: development of pedagogical knowledge; autonomy and empowerment of teachers and students in learning; and meanings of the educational practice of literature teaching. It was found, about the educational practices of literature teachers promoted by the ProEMI, that there is a difficulty in overcoming a more traditional approach and promoting a successful literature teaching. However, some clues present in their statements allow the conclusion that the ProEMI enables some innovations, but these depend heavily on pedagogical knowledge of teachers and their position as subjects and autonomy promoters.
\end{abstract}

Keywords: Educational practices. Literature teaching. Programa Ensino Médio Inovador.

\title{
Resumen
}

El presente artículo presenta resultados de una investigación que tiene como objetivo analizar las prácticas pedagógicas de profesores de literatura en el Programa Ensino Médio Inovador (ProEMI). El soporte teórico se basa en Vygotsky (2002; 2003), Cereja (2005), Cereja y Magalhães (2012); Bakhtin (1988; 1997), así como la Proposta Curricular de Santa Catarina (2014) y las Diretrizes Curriculares Nacionais para o Ensino Médio (2012). La generación de datos fue por medio de entrevistas semiestructuradas con dos profesoras de Lengua Portuguesa y Literatura que enseñan en el ProEMI, en una escuela de la Red Estadual de Santa Catarina. Las categorías de análisis fueron: desarrollo de conocimientos pedagógicos; autonomía y protagonismo de los profesores y estudiantes en el aprendizaje; y significados de la práctica pedagógica y enseñanza de literatura. Se encontró, cuanto a las prácticas pedagógicas de los profesores de literatura promovida por el ProEMI que hay una dificultad en superar un enfoque más tradicional y promover una enseñanza de literatura exitosa. Sin embargo, algunas pistas presentes en sus locuciones permiten concluir que el ProEMI posibilita algunas innovaciones, pero ellas dependen en gran medida de los conocimientos pedagógicos de los profesores y su postura como sujetos y promotores de la autonomía.

Palabras clave: Enseñanza de literatura. Prácticas pedagógicas. Programa enseñanza media innovadora. 


\section{Introdução}

O ensino de Literatura no Ensino Médio, historicamente, tem se constituído um desafio no contexto escolar, no entanto percebe-se uma resistência quando o termo é levado à discussão. Os textos que chegam aos estudantes normalmente são aqueles trazidos pelo livro didático nas aulas de Língua Portuguesa a partir de uma seleção prévia de autores e respeitando uma ordem cronológica. Na tentativa de mudar essa prática, algumas escolas têm buscado desenvolver projetos que incentivem a leitura, mas que nem sempre conseguem desenvolver a competência leitora nos estudantes.

Uma preocupação frequente entre os professores, reforçada pelas ideologias presentes na escola, é com as provas do Exame Nacional do Ensino Médio (ENEM) e vestibulares. Consequentemente, os planos de curso, baseados nos livros didáticos, acabam sendo preparados para esse propósito e as práticas de ensino de literatura, no Ensino Médio, têm sido um modo de ensinar os conhecimentos pertinentes a tais provas.

Segundo os Parâmetros Curriculares Nacionais do Ensino Médio da área de Linguagens, Códigos e suas Tecnologias (BRASIL, 2000) há, ainda, a problemática da divisão que tradicionalmente tem ocorrido com a disciplina de Língua Portuguesa, separando o estudo da gramática, da literatura e da redação. Essa divisão refletiu, por muitos anos, na organização dos livros didáticos e nos vestibulares, levando algumas escolas a oferecerem disciplinas distintas, com um professor específico para cada uma delas.

Partindo do precedente, a pesquisa de que trata este artigo objetiva analisar as práticas pedagógicas de professores de literatura promovidas pelo Programa Ensino Médio Inovador. Para isso, foram realizadas entrevistas semiestruturadas com duas professoras de Língua Portuguesa e Literatura que lecionavam no Programa Ensino Médio Inovador, numa escola da Rede Estadual de Santa Catarina.

Para apresentar os resultados da pesquisa, este artigo foi organizado da seguinte maneira: a primeira parte contextualiza o Programa Ensino Médio Inovador; a segunda apresenta o redesenho curricular no ProEMI; a terceira discorre sobre o contexto no qual se insere a pesquisa e as análises; no final, são apresentadas algumas considerações sobre a pesquisa realizada. 


\section{O Programa Ensino Médio Inovador}

O Ensino Médio é um direito social de cada pessoa, e dever do Estado na sua oferta pública e gratuita a todos. (BRASIL, 2012). As unidades escolares que ofertam o Ensino Médio devem estruturar seus Projetos Pedagógicos (PPs) considerando as finalidades previstas na Lei de Diretrizes e Bases da Educação Nacional (Lei n 9.394/96). Levando isto em consideração, bem como a base teórica de Vygotsky (2002), que considera que todo conhecimento é sempre construído na inter-relação das pessoas, um PP precisa ser construído coletivamente para que atenda às expectativas da escola, dos professores e da comunidade.

Segundo as Diretrizes Curriculares Nacionais para o Ensino Médio (BRASIL, 2012, p. 1-2), essa etapa da Educação Básica tem por finalidade:

I - a consolidação e o aprofundamento dos conhecimentos adquiridos no Ensino Fundamental, possibilitando o prosseguimento de estudos;

II - a preparação básica para o trabalho e a cidadania do educando para continuar aprendendo, de modo a ser capaz de se adaptar a novas condições de ocupação ou aperfeiçoamento posteriores;

III - o aprimoramento do educando como pessoa humana, incluindo a formação ética e o desenvolvimento da autonomia intelectual e do pensamento crítico;

IV - a compreensão dos fundamentos científico-tecnológicos dos processos produtivos, relacionando a teoria com a prática.

Considerando a complexidade dessas finalidades e sabendo-se que a conduta humana não é apenas o produto da evolução biológica, graças a qual se formou o tipo humano com todas as suas funções psicofisiológicas a ele inerentes, mas também o produto do desenvolvimento histórico e cultural (VYGOTSKY, 2002), surge a necessidade de pensar uma educação mais voltada para uma formação integral.

Nesse sentido, o Ministério da Educação (BRASIL, 2009) propõe o Programa Ensino Médio Inovador (ProEMI), cuja finalidade é promover inovações pedagógicas nas escolas públicas visando o fomento de mudanças que se fazem necessárias na organização curricular do Ensino Médio. Tais inovações objetivam a melhoria da qualidade do Ensino Médio nas escolas públicas, sinalizando para os seguintes impactos e transformações: superação das desigualdades de oportunidades educacionais; universalização do acesso e permanência dos adolescentes de 15 a 17 anos no Ensino Médio; e consolidação da identidade desta etapa educacional, considerando a diversidade de sujeitos e oferta de aprendizagem significativa para jovens. 
Com relação à aprendizagem significativa, pode-se remeter à afirmação de Vygotsky (2003) de que a cultura e a prática pedagógica de forma interativa e em plano privilegiado podem atribuir à instrução preponderante papel na constituição da consciência. Em uma visão histórico-cultural do conhecimento, segundo a qual o saber é social e construído nas interações, o professor é responsável por organizar atividades educacionais que possibilitem ao indivíduo criar e, consequentemente, internalizar o conhecimento social.

Nesse sentido, o ProEMI pode ser considerado uma oportunidade para superar estruturas curriculares engessadas e deveria, considerando os investimentos material e intelectual realizados pelos governos federal e estadual, apresentar avanços qualitativos, inclusive no que se refere ao tratamento que se dá à literatura.

\section{O redesenho curricular no ProEMI}

A adesão ao ProEMI, segundo o Documento Orientador do Ministério da Educação (BRASIL, 2014) exige que a escola realize um redesenho do currículo na perspectiva da educação integral e diversidade de práticas pedagógicas. Deverá conter ações a serem incorporadas gradativamente ao currículo para qualificá-lo, tais como disciplinas optativas, oficinas, clubes de interesse, seminários integrados, grupos de pesquisas, trabalhos de campo e demais ações interdisciplinares. Por outro lado, para a efetiva prática do elucidado acima, materiais deverão ser adquiridos, tecnologias educativas contratadas e deverá ser ofertada formação específica para os professores envolvidos na execução das atividades.

Outro aspecto levantado pelo Documento Orientador (BRASIL, 2014) indica que a escola deverá contemplar três "macrocampos obrigatórios" " e pelo menos mais dois "macrocampos" de sua escolha. Assim, serão apresentados a seguir, segundo o documento (BRASIL, 2014, p. 6-7), os macrocampos obrigatórios:

- Acompanhamento pedagógico: linguagens, matemática, ciências humanas e ciências da natureza;

- Iniciação científica e pesquisa;

- Leitura e Letramento;

- Línguas estrangeiras;

- Cultura Corporal;

- Produção e Fruição das Artes;

- Comunicação, Cultura Digital e uso de Mídias e;

${ }^{1}$ Compreende-se por macrocampo um campo de ação pedagógico-curricular no qual se desenvolvem atividades interativas, integradas e integradoras dos conhecimentos e saberes, dos tempos, dos espaços e dos sujeitos envolvidos com a ação educacional (BRASIL, 2014). 
- Participação Estudantil.

[...] As ações dentro de cada macrocampo deverão visar à interação direta com o estudante, podendo também, incluir ações de formação de professores, de gestão escolar e adequação dos ambientes escolares.

Nesse redesenho curricular, dentro da ideia de macrocampos, os conhecimentos e sua produção devem dialogar com a diversidade de contextos que compõem a realidade da vida dos estudantes. Os conteúdos e componentes curriculares devem articular-se entre si, reafirmando a importância de cada um, mas transcendendo as fragmentações presentes no padrão de divisão de disciplinas e tempo de aula.

Quanto ao macrocampo voltado para as práticas de leitura e letramento, o Documento Orientador alerta para o seguinte:

É fundamental que os estudantes desenvolvam habilidades de leitura, interpretação e produção de textos em diversos gêneros, assim é importante ter foco na criação de estratégias para desenvolvimento da leitura crítica e da organização da escrita em formas mais complexas, ampliando as situações de uso da leitura e da escrita, incluindo estudos científicos e literários, obras e autores locais, nacionais e internacionais. (BRASIL, 2014, p. 11).

As ações propostas nesse macrocampo, portanto, estão relacionadas com todas as áreas do currículo e poderão estar articulados a outros macrocampos, programas e projetos, tendo em vista as expectativas dos estudantes quanto à sua trajetória de formação. No caso da literatura, outro macrocampo interessante é o voltado para a produção e fruição das artes, através do qual se pretende ampliar "o desenvolvimento do estudante em aspectos relacionados ao senso estético, à relação entre cultura, arte, trabalho, ciências, relações sociais e com o ambiente, articulando estes nos diferentes campos do conhecimento" (BRASIL, 2014, p. 12).

No entanto, as políticas educacionais, no mundo globalizado, passam por um processo de recontextualização pelos diferentes atores sociais, produzindo discursos híbridos (BALL, 1998; 2001). Sendo assim, em nível local, as secretarias de educação de cada estado elaboram orientações e normas próprias para o funcionamento do programa, que podem possibilitar um currículo mais ou menos aberto às inovações. Além disso, em cada escola, incumbida de realizar o próprio redesenho curricular, o empenho de professores e gestores em reorganizar os tempos e espaços escolares vai repercutir na sua prática pedagógica, inclusive no ensino da literatura. 


\section{O ensino de Literatura para o Ensino Médio}

O ensino de Língua Portuguesa e Literatura para o Ensino Médio precisa estar voltado para a formação de um cidadão autônomo e capaz de interagir com a sociedade na qual vivemos. Além disso, na esfera escolar, a leitura é ferramenta indispensável para a construção de conhecimentos nas mais diferentes áreas e disciplinas. Igualmente, a importância dessa ferramenta fica em torno de todas as esferas sociais. Para Cereja e Magalhães (2012, p. 11), o desempenho dos estudantes do Ensino Médio tem se mostrado insatisfatório quanto ao desenvolvimento de capacidades leitoras.

É o que mostram diferentes instrumentos de avaliação, nacionais e estrangeiros, como o PISA (Programa Internacional de Avaliação de Estudantes), por exemplo, em cujo relatório de 2000 os estudantes brasileiros figuram em último lugar, entre jovens (todos entre 15 e 16 anos) de 32 países. [...] No PISA de 2006, 56\% dos jovens brasileiros ficaram no nível 1 ou abaixo dele, ou seja, são capazes apenas de localizar informações explícitas no texto e fazer conexões simples.

Cereja e Magalhães (2012) argumentam, também, que o ensino da Literatura há mais de um século vem sendo realizado de modo não articulado à leitura direta de textos literários, nem visando ampliar horizontes culturais universais. A história da Literatura precisa ser fio condutor do trabalho, criando diferentes cruzamentos para aproximar autores de diferentes línguas e culturas, literatura e cinema, literatura e música, etc. Porém, os movimentos de leitura se voltam para as relações de literatura de cada tempo e também para os diálogos que a própria literatura trava dentro dela mesma.

Fundamentando o precedente com o dialogismo de Mikhail Bakhtin, temos que:

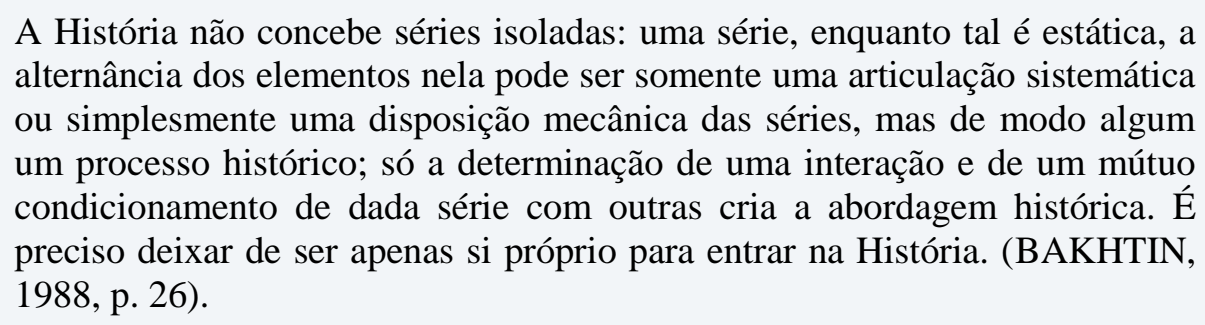

Tomando o ponto de vista de Bakhtin como referência, podemos discutir que o que interessa ao leitor em formação, no caso o estudante do Ensino Médio, são os momentos de formação e de superação da literatura; de consolidação e ruptura. Isto é, interessa o que está vivo, o que está em diálogo com o nosso tempo. Em contrapartida, os projetos de literatura visam aproximá-la do universo do aluno porque, com base em livros, internet, etc., o 
estudante pode organizar diversas atividades acerca de leituras juntamente com o professor, tais como: apresentar seminários, participar de debates sobre obras literárias ou sarau literário, encenar uma peça teatral, expor pesquisas sobre pintores de determinadas épocas, assistir a filmes relacionados com a literatura de cada época, entre outros.

Dentro dessa perspectiva, a literatura deixa de ser algo "ultrapassado" para transformar-se em desafio, em conhecimento significativo, fazendo o estudante de o Ensino Médio compreender melhor o mundo em que vive, pois "o autor é um prisioneiro de sua época, de sua contemporaneidade. Os tempos que lhe sucedem o libertam dessa prisão e a ciência literária tem a vocação de contribuir para esta libertação" (BAKHTIN, 1997, p. 27). Cereja e Magalhães (2012) definem literatura como arte e linguagem, fazendo parte da cultura e

[...] inteiramente integrada com outras linguagens e com o mundo em que vivemos. Vemos literatura em todo lugar. Podemos vê-la nos livros, mas também nos múltiplos diálogos que a arte frequentemente mantém com linguagens e suportes como a tevê, o cinema, os quadrinhos, o cartum, as canções, etc.

Quanto a essas questões, os Parâmetros Curriculares Nacionais + Ensino Médio $(\mathrm{PCN}+)$ afirmam que:

A apreciação estética dos bens culturais produzidos no local, no país ou em outras nações permite que se ampliem as visões de mundo, enriquecendo o repertório cultural dos alunos. A fruição desses bens é também questão de aprendizagem. O conhecimento mais amplo do patrimônio cultural leva a um diálogo mais consistente entre o repertório pessoal e os textos orais e escritos a que o aluno tem acesso e aos que ele produz. (BRASIL, 2002. p. 69).

Considerando a literatura como campo da atividade humana e voltando-se mais para a perspectiva de uma educação integral dos sujeitos, a Atualização da Proposta Curricular de Santa Catarina (2014, p. 29) propõe o seguinte:

Seguramente um percurso formativo que contemple a formação integral precisa criar condições para que os sujeitos, em suas diferentes faixas etárias, vivenciem interações a partir dos gêneros da esfera literária de modo que compreendam como a cultura humana da qual são parte - em grupos mais específicos ou não lhes faculta interagir nessa esfera e nela se enriquecem mutuamente. Formar o leitor de textos em gêneros do discurso do campo da Literatura e, em alguns casos, contribuir para formar também o escritor são processos que requerem essas vivências na escolaridade básica, esse 'provar de interações que se estabelecem entre os sujeitos' na esfera literária. 
Logo, desenvolver com os estudantes do Ensino Médio uma multiplicidade de relações e diálogos mantidos com e pela literatura torna o trabalho dos professores mais significativo para os estudantes, já que aprender literatura por esse viés passa a ser uma maneira de entender, conhecer e gostar da cultura de nosso tempo e integrar-se a ela. Na sala de aula, a literatura sofre um processo de escolarização, mas é de suma importância trabalhar com o texto literário sem torná-lo apenas uma ferramenta para o ensino-aprendizagem e para a gramática. (MARTINS, 2006).

Ainda segundo Martins (2006), o aluno do Ensino Médio precisa aumentar seu repertório de leituras e o conhecimento que tem sobre a estética das obras literárias a fim de alcançar certos conceitos teóricos e literários. O Ensino Médio não traz a literatura para seus estudantes como talvez faça a Educação Infantil, por achar que a necessidade de um não é de outrem, mas urge selecionar literaturas que venham ao encontro das expectativas desse público. Além disso, as técnicas de abordagem dos textos selecionadas costumam carecer de diversificação.

É fundamental que a literatura literária seja abordada na escola, tendo em vista as contribuições da teoria da literatura, as quais certamente podem facilitar a interação do leitor com o texto literário. Alguns autores acreditam que as teorias literárias, embora não tenham contribuído diretamente para a prática escolar, influenciam bastante o contexto de sala de aula. (LAJOLO, 2000, p. 83).

De acordo com essa perspectiva, o professor deveria cotejar os estudantes com os diversos gêneros literários existentes, para que esse perceba que o sentido não está no texto, mas é construído pelos leitores nas interações com o texto. Com isso, estudar a literatura fará sentido para o estudante, porque a partir das interações aparecerão os significados desse trabalho.

Como afirma Rouxel (1996, p.73) citado por Martins (2006), "a escola ainda cultiva uma visão tradicional da literatura, considerada como um conjunto de textos a ser admirada e caracterizada por um 'bom estilo', digno de ser imitado pelos estudantes." O entendimento de literatura como objeto artístico coadjuvante a um processo históricosocial precisa ter maior respaldo em sala de aula para que a escola possa reavaliar a noção de literatura como estética.

A especificidade da obra literária é outro "espinho na bota" da esfera escolar, pois os textos abordados em sala de aula precisam resultar de discursos que se produzem 
cotidianamente. O que diferencia o literário do não literário é a produção, a recepção e a mediação entre autor-texto-leitor. Lajolo (2000, p. 18) discute que

\begin{abstract}
para que seja considerada literatura [...] é preciso algo mais do que interação entre seu autor e seus leitores. A literatura tem que ser proclamada, e só os canais competentes podem proclamar um texto ou um livro como literatura. Entre as instâncias responsáveis pelo endosso do caráter literário de obras que aspiram ao status de literatura, a escola é fundamental. A escola é a instituição que há mais tempo e com maior eficiência vem cumprindo o papel de avalista e de fiadora do que é literatura. Ela é uma das maiores responsáveis pela sagração ou pela desqualificação de obra e de autores. Ela desfruta de grande poder de censura estética - exercida em nome do bom gosto - sobre a produção literária.
\end{abstract}

Como faz notar Zilberman (2001, p. 82) a respeito da literatura estética de "belas letras", "a escola, a crítica literária, a academia e a imprensa são instituições capazes de conferir e legitimar o estatuto de certas produções artísticas em detrimento de outras". Tais entidades passaram a colocar normas e exigências aos escritores.

Por outro lado, Martins (2006, p. 90) acrescenta que a concepção de literatura como "objeto decorativo e belo", transmitida pela maior parte das escolas, reluz-se dentro da sala de aula onde se apresentam apenas obras literárias clássicas produzidas por escritores já consagrados pelo cânon literário. No momento em que a escola privilegia apenas o cânon literário, a abordagem literária de uma perspectiva histórica se amiúda, por desconsiderar o resgate de obras do passado e a análise de obras considerando manifestações sociais e culturais.

Essa dualidade de aspectos está imbricada na cotidianidade escolar desde os primórdios dos tempos, por isso a importância de uma compreensão mais ampla da obra literária para o estudante. A obra literária é produto de um contexto maior, no qual visões de mundo, valores ideológicos de uma época, costumes, lendas, por fim, a variedade de elementos culturais participa ativamente, influenciando a constituição de um texto. Com isso,

[...] é necessário que o estudante compreenda a literatura como fenômeno cultural, histórico e social, instrumento político capaz de revelar as contradições e conflitos da realidade. Ao trabalhar com a leitura literária, o professor pode orientar os estudantes para a função ideológica dos textos [...] a literatura "se alimenta na fonte de valores da cultura". (GONÇALVES FILHO, 2000, p. 104). 
Quanto à visão de literatura como disciplina que correlaciona outras áreas do conhecimento, Martins (2006) alerta que precisa ser bem difundida no contexto escolar, pois a literatura acondiciona relações dialógicas, ou seja, como área do conhecimento, implica ao ato da leitura e à recepção do texto literário.

Em outro modelo Lajolo (2000, p. 15) revela uma visão interdisciplinar da literatura. "Por não saber que excesso de socialismo ou barbárie, todas as nossas disciplinas devessem ser expulsas do ensino, exceto uma, é a disciplina literária que deveria ser salva, pois todas as ciências estão presentes no monumento literário". Para a autora, "a leitura é um objeto largamente transdisciplinar" (2000, p. 16), por isso, qualquer discussão teórica sobre o ato de ler deve considerar a reflexão sob uma perspectiva mais ampla, que envolva as diversas áreas atreladas à prática de leitura como ato político e social.

Nesse sentido, o ensino da literatura não se retém apenas em uma série de textos ou autores, nem em classificá-los dentro de um período literário, e sim atenuar ao estudante o caráter atemporal que tem os textos, bem como a função simbólica e social da obra. Considerando a função social da literatura, retomamos as considerações de Beach e Marshall (1999, p. 17) citadas por Martins (2006), quando mencionam que "o estudo da literatura poderia ser justificado por sua habilidade para ajudar os estudantes a compreenderem a si próprios, sua comunidade e seu mundo mais profundamente”. É essa integração que interessa ao estudante, mas colocá-lo diante do texto literário como objeto lúdico de construção e negociação de sentidos ainda se mostra um desafio no contexto escolar.

O estudante se perde sem saber quais textos ler diante da abundância de textos fragmentados que existem e são apresentados a eles por diversos manuais didáticos. Com isso, como propõe Silva et al (1998), citados por Martins (2006, p. 93):

[...] o ato de ler, para o estudante, torna-se um consumo rápido de textos realizado de qualquer forma e com uma decodificação superficial, assim sem conseguir "ler as entrelinhas"; sem entender as relações intertextuais do texto; reconstruindo o não dito, fazendo inferências, o aluno encara a literatura como algo complexo, difícil de ser compreendido.

Martins (2006, p. 94) aponta dois mitos que ainda assombram o contexto escolar, são eles: "é preciso ler obras literárias para escrever bem e a linguagem literária é marcada pela especificidade". Existe, portanto, o mito de que para que o estudante desenvolva estratégias 
comunicativas e consiga dominar a norma-padrão, precisa ler obras literárias. A intenção estética não é valorizada e modera a liberdade criativa do estudante.

É incentivada, também, a quantidade de obras literárias lidas por ano. Mas, como essas obras estão sendo lidas, já que são consideradas exaustivas para eles? Do outro lado, o estudante fica na expectativa de receber, após a leitura da obra literária, um exercício para efetuar e ser avaliado, como se a competência leitora dos estudantes dependesse de tais exercícios. $\mathrm{O}$ ato de ler precisa ser compreendido como prática social e não um desfecho e/ou "desculpa" para mais um exercício, mais uma avaliação.

Logo, para Martins (2006), os mitos difundem perspectivas ideológicas preconceituosas à ação docente e, subsequentemente, à práxis pedagógica no sentido de estar contribuindo para a formação de leitores acríticos, com visão reduzida nas habilidades intelectuais; transformando-se em uma forma de poder, segregando aqueles cujos alunos não percebem a ação simbólica e transgressora do fazer artístico-literário. Ampliando a discussão dessa perspectiva dos mitos, a partir de Smolka e Nogueira (2013), o trabalho do ensino é visto como um processo multideterminado e multifacetado pelo motivo da implantação de propostas educacionais que afetam e constituem o trabalho docente. No ensino, a sistematização de certos conceitos específicos da teoria e crítica literárias precisa alcançar mais profundidade, exigindo do estudante um repertório mais amplo de leituras e o conhecimento da organização estética da obra literária.

Diante do exposto, a trajetória do ensino da literatura evidencia a necessidade de reavaliação das metodologias, desmistificação do pretexto dado a esse ensino como questões apenas de análise gramatical e das visões estereotipadas acerca das relações entre o texto literário e o estudante leitor. As formas de fixar o texto literário precisam ser repensadas. Se continuarem prevalecendo exercícios repetitivos e fragmentados extraídos de livros didáticos, as aulas de literatura continuarão desinteressantes, os estudantes continuarão a negar os textos, a se desinteressar e se desmotivar diante deles.

\section{Análise dos dados}

Ao apresentar o contexto em que se insere esta pesquisa e as bases teóricas intrínsecas à literatura do Ensino Médio, pontua-se as contribuições do Programa Ensino Médio Inovador à prática pedagógica no que se refere ao ensino da literatura, observando as relações existentes entre os dizeres das duas professoras entrevistadas (os quais foram denominados 
PA e PB) buscando responder à pergunta dessa pesquisa. A seguir, será apresentada as análises dos dados a partir das categorias identificadas: desenvolvimento de saberes pedagógicos; autonomia e protagonismo dos professores e estudantes na aprendizagem; significações da prática pedagógica quanto ao ensino da literatura.

\section{Desenvolvimentos de saberes pedagógico}

A discussão sobre o desenvolvimento de "saberes pedagógico" gera diferentes tipos de conhecimentos que o professor mobiliza ao desempenhar sua ação pedagógica. Evidenciar esses saberes significa reconhecer a existência de uma base de conhecimentos para o ensino, valorizando o saber construído e socializado pelos alunos. Logo, de acordo com PA, é preciso que o estudante busque informações para que possa valorizar aquilo que o professor traz para sala e nem sempre isso acontece. Ele afirma, a respeito de suas expectativas em relação aos estudantes,

[...] que eles aprendam que eles saibam, pelo menos, autores, obras, características de cada escola literária, que é fundamental para eles. O autor e o ano que inicia essa escola literária. Isto é fundamental que eles saibam: características, autores e obras. (PA)

Assim, PA pretende que os estudantes aprendam, pelo menos, autores, obras, características de cada escola literária. Além disso, a ênfase dada à necessidade de "aprender" o autor e o ano de publicação de determinadas obras selecionadas previamente, pode evidenciar a reprodução de uma práxis voltada para a memorização, sem uma interação realmente significativa com esses textos. Essa visão a respeito dos saberes que devem ser ensinados em literatura, comprova a afirmação de Cereja $(2005$, p.89) de que

[...] ensinar literatura brasileira e literatura portuguesa, com base na descrição de seus estilos de época, de suas gerações, autores e obras mais importantes tornou-se um expediente tão comum nas escolas, que para muitos professores é praticamente impossível imaginar uma prática de ensino diferente dessa.

Contudo, o estudante do Ensino Médio precisa aumentar seu repertório de leituras e o conhecimento que tem sobre as obras literárias e a estética, a fim de alcançar certos conceitos acerca da literatura. Nessa etapa da Educação Básica não existe a obrigação de aprofundar os estudantes na teoria da literatura, mas urge selecionar literaturas que venham ao encontro das expectativas desses estudantes para facilitar a interação do leitor com as obras literárias. 
Por outro lado, PB argumenta que, com o aumento da carga horária da disciplina de Língua Portuguesa e Literatura proporcionado pelo ProEMI, com uma aula a mais por semana, o estudo da teoria da literatura pode ser aprofundado. Logo, PB direciona suas aulas no sentido de trabalhar a produção de texto usando obras literárias brasileiras. E afirma:

São poucas aulas. Porque tem muita coisa. Daí você quer passar só o básico. Como tenho o terceiro inovador, essa aula da tarde eu tenho pegado bastante pra trabalhar texto [...] bastante interessados. Separamos: a aula da tarde é sempre produção de texto. Porque daí eu já pego um texto de literatura. Estava trabalhando Graciliano Ramos. Falava da seca, miséria. Aí eu peguei o tema [...] e a gente fez na aula da tarde, mais produção de texto. Daí eles queriam de novo, né, todo dia, um espaço pra dissertação [...] Uma aula a mais já faz diferença, né. (PB)

Essa tentativa de aproximar clássicos da literatura ao cotidiano dos estudantes, aproveitando-os para o trabalho de produção de textos de gêneros não literários, a exemplo dos textos dissertativo-argumentativos, demonstra que o texto literário passou por um processo de escolarização. Soares $(1999$, p. 25) distingue dois tipos de escolarização do texto literário: uma adequada, que atenta eficientemente para as práticas de leitura atuantes no cotidiano social; e uma inadequada, que ocorre insistentemente em sala de aula, promovendo uma aversão dos estudantes aos livros, sobremaneira destituindo as práticas sociais de leitura desse contexto.

A partir dos saberes pedagógico, privilegiar um dos tipos implicará diretamente nos resultados de aprendizagem. É o que pode acontecer com PB, visto que o texto dissertativoargumentativo é um gênero textual basicamente escolar, geralmente ensinado e praticado no ensino médio como uma preparação para o ENEM e vestibulares. Essa transposição do texto literário para um gênero mais escolarizado se for algo sistemático e frequente, pode distorcer a visão dos estudantes a respeito da literatura.

Outra visão tradicional da literatura, como afirma Rouxel (1996), citado por Martins (2006, p. 73), consiste em considerá-la como um conjunto de textos a ser admirado, e caracterizado por um "bom estilo", digno de ser imitado pelos estudantes. PB demonstra que Rouxel está certo quando afirma que a escola ainda visiona um modo tradicional de trabalhar a literatura porque, em sua fala, deixa claro que a importância principal das aulas de Língua Portuguesa é trabalhar os textos clássicos para que o aluno disserte sobre o texto mais tarde.

Além disso, tentativas de conciliar a leitura do texto literário com o ensino da teoria da literatura podem ser bastante desafiadoras, como se pode constatar na seguinte fala: 
Eu, às vezes, faço comentários dos escritores e tem uma parte que eu faço muito eles lerem em sala de aula, os fragmentos de livros. Eu pego, assim, tipo, cada um [...] um parágrafo, até o ponto final. Uma forma de participar. Senão, aquele que não participa, ele está sempre longe. É o que eu mais tenho de prender eles. Eles não ficam nem interessados. Aí, quando eles vão fazendo a leitura, eu vou fazendo umas perguntas a respeito, uns comentários. (PB)

Segundo Beach e Marshall (1999 apud MARTINS, 2006, p. 84)

A leitura da literatura está relacionada à compreensão do texto, à experiência literária vivenciada pelo leitor no ato da leitura, ao passo que o ensino da literatura configura-se como o estudo da obra literária, tendo em vista a sua organização estética. (grifos dos autores)

Desse modo, mesmo que os níveis estejam relacionados com o objeto esteticamente organizado, a escola dissocia o prazer de ler do reconhecimento das singularidades estéticas da obra. Os dois modos de "ver" a literatura precisam estar presentes no cotidiano escolar de modo harmonizado, pois se relacionam entre si.

Seria interessante, nesse aspecto, voltar-se para as práticas de leitura literária desenvolvidas por professores da Educação Infantil, nas quais prevalecem a fruição, a descoberta, a apreciação estética e o prazer. Na direção contrária, a fala de PB revela o desinteresse dos estudantes do ensino médio pelos fragmentos de texto apresentados. Sua técnica de leitura oral em sala de aula parece transformar todo texto literário em um mero objeto de estudo que, distante dos seus usos sociais, pode não ser significativo ao estudante.

\section{Autonomia e protagonismo dos professores e estudantes na aprendizagem}

Incontestavelmente, o professor e seus materiais pedagógicos, como mediadores da aprendizagem, precisam estar articulados com a natureza deste empreendimento educacional, adotando uma postura interacionista e materiais de aprendizagem potencialmente significativos.

Nesse sentido, PA evidencia a importância de os alunos trabalharem com a literatura que escolheram em rodas de leitura. Ela cogita que a técnica de momentos de "leituração" faz com que os alunos vão se desinibindo para falar em público e aprendem a ler, interpretar e conhecer escritores (grifo nosso). Ainda com essa técnica, PA incita a autonomia dos estudantes no momento da escolha da obra, tanto para leitura, quanto para a compra. A 
aprendizagem se sustenta no protagonismo dos estudantes em contar o que leram na literatura escolhida para os demais colegas na roda. Percebemos que a autonomia e o protagonismo de PA existem no momento em que pode planejar, registrar e avaliar a maneira como vai trabalhar o texto literário com os estudantes. Nesse sentido a professora discorre,

Eu observo, assim, essa questão. Eu até trabalho com eles, eles fazem a roda de leitura. Então envolve toda essa questão da literatura. Que eles têm que ler um livro, no mínimo um por bimestre, e tem que apresentar esse livro. Um breve relato, assim, um resumo bem sucinto, só oralmente [...] Eu deixo os títulos a escolha deles. Porque se eu escolher, ou passar uma lista, sempre vai ter aqueles que vão dizer, "ah, não tem nada que eu gosto". Então eles têm, toda semana, semana sim, semana não, nós temos o cronograma da biblioteca, a última folhinha ali exposta. Aí eles vão à biblioteca na minha aula. Eu levo todos juntos, vão todos juntos. Aí lá eles têm as estantes que eles podem pegar os livros paradidáticos que eles possam estar lendo e daí lá eles escolhem [...] Aí, sim, aí eu peço sugestões pra eles, para a compra [...] Daí eles começam a se desinibir um pouquinho, pegar essa questão de falar com os colegas de sala, que são os colegas que eles convivem tantas horas por dia. Trabalhar a questão, então, da oralidade [...] (PA)

Com essa fala, PA demonstra uma preocupação em inovar sua prática de ensino da literatura e refletir sobre ela. Sua autonomia em tentar algo novo, estimulando que os alunos falem sobre as leituras realizada, bem como a valorização dos gostos e interesses dos alunos quanto à escolha de obras, é muito importante dentro da proposta do ProEMI. No entanto, dentro do macrocampo de Leitura e Letramento, poder-se-ia ir além, buscando formas mais flexíveis, interdisciplinares e inovadoras de fazer essa roda de leitura, para que não se torne simplesmente uma obrigação escolar.

Em se tratando do uso das tecnologias, conforme PA o estudante tem autonomia para trabalhar com os recursos midiáticos, no que diz respeito às obras literárias, em sala de aula, desde que aborde aquilo que precisa para aprender. No entanto, garante que a aprendizagem é mais efetiva se "pegar o livro para ler, ver tipo de letra, como é a capa." (grifo nosso) Constatamos que PA demonstra um saber docente acerca das tecnologias de informação e comunicação já consolidado, ou seja, evidencia em sua fala a dificuldade de aprender com os estudantes, não compreendendo a intersubjetividade como meio de aprendizagem entre pares.

Ah, sim. Eu sempre mostro [...] Pode pegar pelo digital e tudo, mas [...] Tinha um aluno do nono ano [...] Nada como pegar bem na capa, no papel, pra sentir. Aquilo lá me chamou a atenção. Eu também olho a consistência da folha, o tipo de letra, capa. Teve um dia, às vezes pra fazer eles dizer assim 'Ah, poderia ler tal livro'. Aí até teve um dia, a gente pegou, o pessoal tem quase tudo: internet, né, o celular, [...] aí eu pedi para eles pegarem, 
pesquisarem, um pedaço, outro. Porque tu não vai obrigar só ler o de papel, ali, se as coisas estão mudando, né.(PB)

Além disso, posicionamento de PB quanto aos textos em formato digital, caracterizam uma resistência às novas tecnologias e a portadores textuais não tradicionais. Inclusive o uso da internet e do celular, que são tão presentes no universo dos estudantes dessa faixa etária, são pouco explorados por PB, aparentemente por não acreditar que são ferramentas com grande potencial para a aprendizagem dos estudantes.

Ao discorrer sobre as possibilidades de desenvolver a autonomia do estudante enquanto leitor, PB afirma:

Eu gosto de ler os textos, comentar, pedir o que eles acharam, até fazer descrição de personagem [...] É uma forma de tentar fazer com que ele imagine como que era aquele personagem. E alguns fizeram bem feitinho. Aqueles que não vão tão bem são a decepção do professor. (PB)

Para Martins (2006, p. 85), a teoria da literatura precisaria estar na voz do estudante para não ser deliberadamente afastada dos roteiros de interpretação, pelas fichas de leituras, pelos exercícios propostos pela professora e pelo livro didático. A estratégia usada por PB para a caracterização dos personagens, através da descrição, pode ser bastante útil se estiver relacionada com o contexto histórico e cultural do estilo de época ao qual está inserido. Assim, o desafio do professor é ajudar os estudantes a interpretar e reinterpretar textos literários dos mais variados gêneros, sem a instituição de "tarefas prontas e acabadas sobre esses textos".

\section{Ressignificações da prática pedagógica quanto ao ensino da literatura}

Geralmente é no Ensino Médio que o estudante passa a ter um maior contato com o estudo sistematizado da literatura, transmitido através da apresentação de uma série de textos ou fragmentos e de autores classificados como pertencentes a um determinado período literário. Contudo, a busca por esses textos e autores, na maioria das vezes, é realizada pelo professor. Ao estudante, cabe a tarefa, a muito tempo, de esperar o conteúdo vir por intermédio do mediador da aprendizagem.

No que se refere, PA ambiciona que o desenvolvimento do estudante, para uma efetiva aprendizagem, consista em "buscar mais informações sozinho, ser autor do seu ensino, saber 
trabalhar em grupo, quando de atividades em grupo não faltar à aula, enfim, o estudante precisa se posicionar quanto ser" na sala de aula para poder aprender. Assim, PA alega,

\begin{abstract}
Nós trabalhamos, assim, a gente procura fazer alguma coisa diferenciada. $\mathrm{O}$ que a gente consegue, assim, realmente dar [...]. No fim a gente tem até um pouquinho de receio, de trabalhar muito diferente, porque esse muito diferente, como eu falei antes, ele pode interpretar de uma forma errônea, diferentemente. Ah, ele acha que o professor está nos deixando trabalhar assim, assim [...] Ele também tem que ir a busca das informações e valorizar isso também. Então, a gente não estende muito não. O que... que falta para eles, pra trabalhar essa questão ali, pra trabalhar essa questão de grupo, ali. (PA)
\end{abstract}

Aí falam de tudo quanto é assunto durante a aula, menos o trabalho que tem que ser feito. Porque daí nós combinamos, ó: eu faço isso, você isso, e isso. Deu. O trabalho fechou. Daí, ah, tem que apresentar o trabalho. Aí quando você vai para a socialização, a apresentação de trabalho, o que acaba acontecendo? Aí falta alguém do grupo: 'Professor, não podemos apresentar, porque faltou Fulano, Beltrano e Cicrano' [...]. (PA)

Por meio dos dizeres de PA, podem-se perceber algumas tentativas de trabalho diferenciado, especialmente propondo atividades em grupos. No entanto, parece haver uma dispersão dos estudantes nessas ocasiões e uma falta de comprometimento com a própria aprendizagem. Nesses casos, faz-se necessária uma preocupação redobrada com o planejamento, isto é, com a definição de objetivos de acordo com as necessidades do grupo, com orientações claras quanto à sua realização, bem como critérios bem definidos para a avaliação.

Quanto aos objetivos de aprendizagem, segundo PB, o estudante sabendo ler, comentar o que leu e interpretar, consegue viver no mundo de trabalho. Logo ela constata:

Ter uma boa leitura, saber interpretar, saber comentar sobre o que leu, também eu acho muito interessante. Porque, na maioria das vezes, você pede e tem gente que não sabe nem o que leu. Isso eu acho fora de cogitação, mas acontece. (risos) E bastante, né. (PB)

Nisso consiste um grande desafio do professor de Língua Portuguesa e Literatura, promover práticas de letramento realmente significativas para desenvolver as capacidades de produção de textos orais e escritos com expressividade, bem como a compreensão dos textos com os quais interage. Infelizmente, ainda é muito comum o ingresso de estudantes no ensino médio num nível letramento bem abaixo do esperado, dificultando, e muito, a realização de atividades envolvendo a literatura. 
Considerando os dizeres analisados, evidenciam-se algumas iniciativas de ressignificação da prática pedagógica no ensino de literatura por professores do ProEMI. Porém, dentro da proposta de novos tempos e espaços para a aprendizagem, com uma maior flexibilidade do currículo, planejamento coletivo e ampliação da carga horária, os esforços empreendidos ainda parecem modestos frente às possibilidades apresentadas.

Nesse sentido, Martins (2006) defende que urge uma nova proposta curricular, com mudanças no sentido de repensar constantemente a prática pedagógica com base em algum suporte teórico-metodológico. Portanto, para que os professores possam articular teoria e prática no ensino da literatura, se fazem necessárias algumas contribuições: desmistificar a concepção escolarizada como fenômeno decorativo, belo; incentivar o trabalho com textos clássicos e contemporâneos; reavaliar enfoques, como estruturalismo, formalismo, biografismo e outros; evitar trabalhar a literatura apenas por meio de textos fragmentados; considerar a diversidade de leituras produzidas pelos estudantes em contextos não escolares; diversificar os trabalhos com textos do ponto de vista didático-pedagógico; desenvolver análises comparativas entre textos produzidos por autores diversos em contextos distintos; a partir do trabalho com a intertextualidade, incentivar a produção de resenhas, paródias, resumos de textos literários, sendo o estudante coprodutor do texto a partir da leitura; dissociar a leitura do texto literário de análises puramente gramaticais, estilísticas, etc.

Vale, ainda, considerar as escolhas pessoais dos estudantes em momentos adequados, desvinculando-se o ato da leitura das práticas escolares; considerar a diversidade de textos pertencentes a gêneros e épocas diferentes; estabelecer comparações entre a leitura literária no espaço cibernético e a leitura do texto impresso; investir no ensino da literatura a partir de uma perspectiva intersemiótica, promovendo o diálogo da literatura e outras artes e, por fim, valorizar as histórias de leitura dos estudantes (MARTINS, 2006).

\section{Algumas considerações}

O Ensino de Literatura no Ensino Médio continua sendo um desafio, uma preocupação presente entre os professores sobre o que ensinar, como ensinar, por que ensinar e para que ensinar. Nessa busca, o professor ainda se vê preso a uma postura bastante tradicional, dividindo as aulas de Língua Portuguesa em estudo da gramática, literatura e redação, bem como elaborando seu planejamento a partir dos textos, conteúdos e atividades propostos nos 
livros didáticos. Isso se deve, em parte, pela preocupação em preparar os alunos para as provas de vestibular e para o ENEM, priorizando os conceitos pertinentes a tais avaliações.

Nesse contexto, o ProEMI desponta como uma proposta de reorganização curricular para as escolas de Ensino Médio, visando promover inovações pedagógica e melhoria da qualidade do ensino nas escolas públicas. Teoricamente, constitui-se num terreno propício para a superação de currículos engessados e práticas pedagógicas que não atendem mais às necessidades dos estudantes, possibilitando, assim, novas formas de fazer o ensino da literatura.

A presente pesquisa permitiu compreender que a prática pedagógica dos professores de literatura depende, em grande parte, dos saberes pedagógicos que sustentam seu trabalho e seu desenvolvimento profissional. Uma formação inicial focada em concepções mais tradicionais do ensino da literatura resultará em práticas que acabam afastando o estudante do texto literário.

Torna-se indispensável, portanto, estudo e reflexão constante acerca do objeto de ensino para ultrapassar as barreiras que impedem uma nova postura profissional, mais voltada para o estudante enquanto sujeito da própria aprendizagem, inserido num contexto histórico, político, cultural, econômico e social. Postura essa constituída como promotora de autonomia e protagonismo, tanto do estudante quanto do professor em relação à própria aprendizagem.

Em síntese, os dizeres das professoras pesquisadas evidenciaram que ainda é cedo para afirmar que o ProEMI promove ressignificações na prática pedagógica do ensino de literatura na escola investigada. Embora haja uma disposição dos docentes nessa direção, desafios inerentes ao seu trabalho emergem das suas locuções, principalmente no que se refere aos seus saberes pedagógicos e à sua atuação enquanto sujeito autônomo e promotor da autonomia dos estudantes.

No entanto, constata-se que o ProEMI abre algumas possibilidades que, se bem aproveitadas no âmbito escolar, poderão promover um novo olhar sobre o ensino da literatura e uma nova prática pedagógica. Entende-se que, assim, será possível formar cidadãos que, mais do que leitores, compreendam a multiplicidade de interpretações possíveis e sejam apreciadores dos textos literários.

\section{Referências}

BAKHTIN, Mikhail. O problema do texto. In: Estética da criação verbal. 2. Ed. São Paulo: Martins Fontes, 1997, p. 366. 
BAKHTIN, Mikhail. Marxismo e filosofia da linguagem. (trad. Michel Lahud; Yara F. Vieira). São Paulo: Hucitec, 1988.

BALL, Stephen J. Big policies/small world: an introduction to international perspectives in education policy. Comparative education, v. 34, n. 2, 1998, p. 119-130.

BALL, Stephen J. Global policies and vernacular politics in education. Currículo sem fronteiras. V. 1, n. 2, p. 99-116, dez. 2001.

BRASIL. Lei 9.394. Lei de Diretirzes e Bases da Educação Nacional. Brasília: 20 de dezembro de 1996.

BRASIL. Parâmetros curriculares nacionais (ensino médio). Parte II: Linguagens, códigos e suas tecnologias. Brasília, 2000.

BRASIL. MEC/SEMTEC Parâmetros curriculares nacionais + ensino médio: orientações educacionais complementares aos PCN. Brasília, 2002.

BRASIL. Programa Ensino Médio Inovador - Documento Orientador. Brasília, DF, 2014. BRASIL. Resolução CNE/CEB n. 2. Diretrizes Curriculares Nacionais para o Ensino Médio. Brasília, 30 de janeiro de 2012.

BRASIL, Resolução CNE/CP n. ${ }^{\circ}$ 11/2009 Proposta de experiência curricular inovadora do Ensino Médio. Brasília, 30 de junho de 2009.

CEREJA, William Roberto. Ensino de literatura: uma proposta dialógica para o trabalho com literatura. São Paulo: Atual, 2005.

CEREJA, William Roberto; MAGALHÃES, Thereza Cochar Magalhães.

Português: linguagens - Ensino Médio. Manual do Professor. v. 1, 8 ed. São Paulo: Atual, 2012.

GONÇALVES FILHO, Antenor A. Educação e literatura. Rio de Janeiro: DP\&A, 2000.

LAJOLO, Marisa. Do mundo da leitura para a leitura de mundo. 5 ed. São Paulo: Ática, 2000 .

MARTINS, Ivanda. A literatura no ensino médio: quais os desafios do professor? In: BUNZEN, Clécio; MENDONÇA, Marcia; KLEIMAN, B. Angela (org.). Português no ensino médio e formação de professor. São Paulo: Parábola, 2006.

SANTA CATARINA. SECRETARIA DE ESTADO DA EDUCAÇÃO. Proposta Curricular de Santa Catarina: formação integral na educação básica. Florianópolis, 2014.

SILVA, et al. Apropriação Cultural e Mediação Pedagógica: Contribuições de Vygotsky na Construção do Tema. v. 16, n.2, p. 219-228, abr/jun. 2011. 
SMOLKA, Ana Luiza Bustamante; NOGUEIRA, Ana Lúcia Horta Nogueira (org.). Estudos na perspectiva de Vygotsky: gênese e emergência das funções psicológicas, 1 ed.

Campinas, S.P.: Mercado de Letras, 2013.

SOARES, Magda Becker. A escolarização da Literatura Infantil e Juvenil. In:

EVANGELISTA, Aracy, et al. (Orgs.). A Escolarização da Literatura: O Jogo do Livro Infantil e Juvenil. Belo Horizonte: Autêntica, 1999.

VYGOTSKY, Lev Semenovich. A formação social da mente: o desenvolvimento dos processos psicológicos superiores. Tradução José Cipolla Neto, Luís Silveira Menna Barreto, Solange Castro Afeche. 6. ed. São Paulo: Martins Fontes, 2003.

ZILBERMAN, Regina. Fim do livro, fim dos leitores?; Coord. Benjamin Abdala Junior, Isabel Maria M. Alexandre. São Paulo: Editora Senac São Paulo, 2001

Ms. Silvia Paulo

Universidade Regional de Blumenau - Brasil

Rede Municipal de Educação de Rio do Sul

Bolsista da CAPES

E-mail: sipari_g@hotmail.com

Ms. Ricardo Inocênio Pereira

Universidade Regional de Blumenau - Brasil Bolsa do Programa UNIEDU/FUMDES Pós-Graduação

Rede Estadual de Educação de Santa Catarina

E-mail: pricardopereira@ @otmail.com

Dr ${ }^{a}$ Rita Buzzi Rausch

Universidade Regional de Blumenau - Brasil

Doutora em Educação pela UNICAMP

Programa de Pós-Graduação em Educação

E-mail: ritabuzzirausch@gmail.com

Dra Marcia Regina Selpa Heinzle

Universidade Regional de Blumenau - Brasil

Doutora em Educação- UNICAMP

Professora e Pesquisadora no Programa de Pós-Graduação em Educação

E-mail: selpamarcia@gmail.com

Recebido em: 18 de dezembro de 2015

Aprovado em: 07 de setembro de 2016 